\title{
BRUCE LINCOLN'S PHILOSOPHY
}

\author{
Kevin Schilbrack
}

\section{Introduction}

The title of my paper is polemical. For this reason I want to begin with a brief sketch and justification for what I am aiming to do.

My view is that historians, anthropologists, and others who develop theories about religion always also develop philosophies. In order to study religions, one must at least implicitly have answered certain questions about what one takes to be real and not real, knowable and not knowable, and good and not good. In other words, scholars of religion, like all human beings, live and act with certain metaphysical, epistemological, and axiological presuppositions. Now, one way of understanding the task of philosophers - a way I endorse - is the Socratic task of making one's metaphysical, epistemological, and axiological presuppositions explicit, and assessing them. I take this to be Socrates' typical goal in his dialogues. He seeks to get people who are about their nonphilosophical business to make explicit and to critique the assumptions and values according to which they do what they do. The philosopher's task on this model might be called "presuppositional analysis." On this view, although not everyone assumes the philosopher's task of explicating presuppositions, everyone has a philosophy.

Of course, there are other views of the relation of philosophy to history and other empirical disciplines. Eor example, in the positivist understanding of the sciences (understanding "sciences" in the broad sense so that it includes history), the scientist could give a descriptive account of a given phenomenon that is not involved in philosophical questions, an account of the data that is philosophically neutral. For the positivist, one's observation sentences can be separated from one's values; one can restrict oneself to just the facts. On this view, the historian who studies religion could then describe the phenomenon of religion without raising, even implicitly, any metaphysical, epistemological, or axiological questions. For the positivist, it makes little sense to speak of a historian's philosophy. The two fields of history and philosophy differ and their questions have no overlap. On this understanding, also, it is 
possible to insist that the study of religion should exclude nonscientific approaches to the data, that it should be resolutely scientific and leave views of the real, the true, and the good to theologians.'

On my anti-positivist view, however, the scientific and the philosophical can be distinguished, but they cannot be separated. This is because a scholar's views are always from somewhere, which is to say that they are not philosophically neutral. They embody a particular set of normative assumptions. On this view, which I am recommending, scholars study their data from a particular perspective, and this perspective is always already established in part by their answers to metaphysical, epistemological, and axiological questions. ${ }^{2}$ Just as "descriptions are theory-laden," then, I am proposing that definitions, comparisons, and explanations of religions are philosophy-laden.

On this understanding, it follows that the difference between the scientific study of religions and philosophy is not the difference between those who do and those who do not hold metaphysical, epistemological, and axiological positions. The difference is rather that between those who hold such positions implicitly and uncritically and those who hold them explicitly and critically. The scientific study of religion, like any human practice, implies the willingness to make one's presuppositions explicit whenever this is necessary and appropriate. Thus, the difference can be put this way: the philosophers of religion bear what might be called proximate responsibility for presuppositions - making them explicit is their primary task - but historians of religion bear this responsibility remotely - it becomes their task only when their presuppositions are put in question, for example, when an opponent objects that they obscure some part of the data. One can also say that, whereas philosophers of religion have the responsibility to explicate their presuppositions systematically, which is to say, not only to identify but also to defend them, the scientific student of religion has the nonsystematic responsibility merely to identify them. As a consequence, those who argue that the study of religion should be resolutely scientific are arguing, in effect, not that the study of religion should avoid taking positions on nonscientific questions about the nature of the real, the true, and the good, but rather that the positions that scholars do take should remain implicit and undefended.

This scems to be the view of Wicbe (1999).

There are of course non-philosophical presuppositions implicit in scholarship as well; for example, scholars may give an account of their data from a perspective informed by presuppositions about gender and class. I am not claiming that philosophical discourse is free from such presuppositions. 


\section{Lincoln on "belief"}

Let me now turn more fully to Bruce Lincoln and to what I am alleging is his implicit philosophy. In particular I want to focus on what can be called Lincoln's epistemology. ${ }^{3}$ In this section of the paper, I focus on his view of the nature of belief, about which he makes passing comments that point towards his philosophical sympathies. In the next section, I focus on his view of experience, about which he, loudly, says nothing. ${ }^{+}$

In "The Study of Religion in the Current Political Moment," Lincoln cites Talal $\Lambda$ sad's influential critique of Clifford Geertz's definition of religion (Lincoln 2003: 1-3). Lincoln notes that Asad's critique has two parts, first a critique of Geertz's definition of religion as too focused on the category of "belief," a critique which Lincoln seems to accept, and second an argument against the very idea of defining religion, an argument which Lincoln rejects as too radical. Before I turn to Lincoln's discussion of "belief," I want briefly to note the way that Lincoln handles $\Lambda$ sad's more radical argument, because I think that it offers a valuable strategy for how to negotiate such questions, namely, by finding a via media between two extremes.

On the question whether religion can be defined at all, one can imagine two opposed answers. In the first place, there are some who argue that our definitions capture the essence of the defined object and, on this view, definitions of religion identify the essence of religion. $\Lambda$ sad objects, however, that the very idea that religion has some circumscribable essence is an idea that only emerged at a specific time and place in history, namely, after the religious sphere was delimited in Christian Europe by the Treaty of Westphalia in 1648 (Asad 1993: ch. 1). The notion that religion is the kind of thing that can be defined is therefore not self-evident, but rather reflects the particular historical and political circumstances of the modern secularizing West. Eor a scholar to continue this project of "defining religion" would be to participate in discursive practices that are implicated in recognizable ways to modern Christian apologetics and colonialist politics.

In his response, Lincoln does not reject $\Lambda$ sad's deconstruction or historization of defining religion, but he does not accept the conclusion

\footnotetext{
3 Making explicit Lincoln's implicit axiology, including his implicit political philosophy, would be equally valuable and would, I suspect, reveal even greater agreement between his views and mine.

+ This scction draws inspiration from Godlove 2002.
} 
that all such definitions are illegitimate. The fact that any definition will be "the historical product of discursive processes," Lincoln says, "hardly renders futile all efforts at definition, however, particularly when one understands these as provisional attempts to clarify one's thought, not to capture the innate essence of things" (2). Lincoln thus detaches the conceptual link between definitions and essences, and proposes his own, nonessentialist definition. Schematically, then, one can frame Lincoln's position as a kind of golden mean or via media. On one side, there are those who use definitions of religion and who see them as identifying an essence. On the other side, there those like Asad who reject definitions of religion because they discount the possibility of an ahistorical essence. Lincoln partially agrees with both sides; that is, he agrees with both the modern project of defining religion and with the postmodern suspicion towards essences. Similarly, one might say that Lincoln partially disagrees with both sides, that is, with both modernist essentialism and postmodern rejection of definitions. Where the defining essentialist has two yesses and the anti-definitional anti-essentialist has two no's, Lincoln has a yes and a no. This is why I called his approach a via media, and $I$ consider it a good strategy when considering a debate between two sides, both of which house an important insight (cf. Hartshorne 1987).

On Asad's second argument, however, the one in which he argues that Geertz's definition of religion is too focused on belief, Lincoln seems largely persuaded. It is a shame because Geertz's definition of religion never mentions belief at all; "belief" is not an especially important term in Geertz's vocabulary. Nevertheless, Lincoln concurs with Asad "that Geertz made interiority the locus of the religious" (1). He suggests that this is indicated by the nouns Geertz does use in his definition: symbols, moods, motivations, and conceptions. What we want, Lincoln says, is an understanding of religion that does not slight those religions "that are oriented less toward 'belief' and the status of the individual believer" (1). In place of Geertz's definition, therefore, Lincoln recommends an understanding of religion that does not cover up its social and political dimension. Lincoln offers a definition of religion as consisting of four domains: discourse, practice, community, and institution. ${ }^{3}$

\footnotetext{
"Lincoln defines religion as consisting of these four parts: " 1 . A discourse whose concerns transcend the human, temporal, and contingent, and that claims for itself a similarly transcendent status...2. A set of practices whose goal is to producc
} 
Recall that my interest is in arguing that Lincoln is, at least implicitly, involved in epistemological questions. One sees such involvement especially, I would like to argue, in the first domain of Lincoln's definition, where he replaces the traditionally central category of religious belief with religious discourse. His reason for this switch is worth quoting in full:

My preference for "discourse" over "belief" is based on two arguments. First is an epistemological consideration. Students of religion have no unmediated access to the beliefs of those they study, nor to any other aspects of their interiority. Rather, we come to know something of those beliefs only as they find external (always imperfect and sometimes quite distorted) expression in acts of discourse and practice. Regarding that of which one can have no direct knowledge, scholars cannot speak with any confidence and should in their professional capacity, at least perforce remain silent. Second, an ontological and ontogenetic observation: Belief almost never arises de novo in pristine interior reflection and experience, but generally follows exposure to the discourse of significant others. These include parents, above all, but also friends, family and clergy, who signal what they believe and what they (also the institutions and traditions to which they belong) belicve ought be believed. As these statements are received and metabolized by those to whom they are addressed, they are internalized as beliefs, but in this process, discourse is both logically and chronologically prior to belief $(111$, n. 15).

In short, belief is private and therefore inaccessible, and so the student of religion will do better to attend to religious discourse, which is public.

Lincoln's recommendation that students of religion replace "belief" with "discourse" can be best understood, I think, if we place it in relation to a larger debate about the place of "belief" in the study of religions. As I did with his discussion of defining religion, I want to place it in the context of two positions that identify what I take to be the poles of the debate. On the one side, there are those who argue that the category of belief bas a privileged or even essential role in the study of culture. ${ }^{6}$ And one can give a good reason for this position: one can

a proper world and/or proper human subjects, as defined by a religious discourse to which these practices are connected. ...3. A community whose members construct their identity with reference to a religious discourse and its attendant practices... 4. An institution that regulates religious discourse, practices, and community, reproducing them over time and modifying them as necessary, while asserting their eternal validity and transcendent value" $(5-7)$.

"To take two classic examples among many, Edward Burnett Tylor defines religion as the "belief in spiritual beings," and William James defines it as "the belief that there is an unseen order, and that our supreme good lies in harmoniously adjusting oursclves thereto." 
argue that it is precisely the agent's belief that makes an activity the activity it is. $\Lambda$ n activity is a religious activity, for example, only if it is informed by a religious belief. For this reason, it is crucial that the student of culture understand the beliefs of those she studies. $\Lambda$ second step typically follows: if beliefs are interior mental states, then the student of culture also needs some means to "get inside the heads," so to speak, of the people she studies, for example, through participant observation, honest informants, or careful intuition.

The opposite position excludes belief. Those in this position argue that the category of belief is not crucial to religion. I take it that this is the position of Donald Lopez, Jr., who objects to "the idea that a religion must have beliefs in order to be a religion" (Lopez 1998: 29). Lopez argues that attributions of belief, a "nebulous" and "elusive interior state" (27, 21), serve as a "substitute," "mask," or "surrogate" (21, $21,27)$ for economic interests. Lopez gives the example of the martyrdom of Peter of Verona. Though Peter is eulogized for being killed for his beliefs, Lopez proposes that religious beliefs played no role: "Peter was murdered not for his beliefs but for his deeds, specifically for the confiscation of the property of two Cathar noblemen" (26). Thus, as analytic philosophers might put it, belief is a propositional attitude, but property is not a proposition, and confiscating it is not an attitude. In an argument like $\Lambda$ sad's, then, Lopez argues that the assumption that religious actions and institutions must have beliefs in order to be religious is "neither natural nor universal. It might be described as an ideology, not so much in the sense of false consciousness but as an idea that arises from a specific set of material interests" (28). According to Lopez, this ideology of belief reflects the particular interests of European Christianity. To assume that religions outside that sphere of influence involve beliefs is to introduce belief "into domains where it was not previously present" (29), and Lopez points to Buddhism in nineteenth-century Sri Lanka as an example of a religion that allegedly operated without beliefs. Thus Lopez is not arguing that there are some religions in which statements of faith are less central or that religious beliefs support material interests; those claims are uncontroversial. His claim is rather that the study of religion (at least, perhaps, outside the study of modern Christianity) does not need to include the category of "belief" at all.

Where does Lincoln stand in relation to these two poles in the debate? One might think that he stands with Lopez in the second position. $\Lambda$ fter all, Lincoln does want us to drop the category of "belief," and the reason he gives is that belief is private, interior, and so inaccessible 
to the historian, whereas discourse is public. But the complete rejection of belief is not Lincoln's view, and I will argue that it is not a view anyone should take.

The problem is that the two polar positions on belief (like the two positions on definition) are contrary and so while both cannot be right, both can be wrong. There is a third, middle position, as yet unappreciated. This is easy to see, I think, if we give the first position the overly simple label of the "private/belief" position and we call the second position the "public/anti-belief" position. What is wrong with both positions is that they assume that belief is something private. They both assume that a belief is an interior mental state, and therefore, to know what another believes it is necessary to get inside that person's head. Clearly, a via media is possible if it makes sense to speak of such a thing as "public belief." And, as a matter of fact, arguing that belicfs are public has been a central theme of twentieth-century philosophy. It is actually a point of agreement between analytic philosophers and Continental philosophers. Thus we have Wittgenstein arguing that there can be no private language because meaning is necessarily social, and Sartre arguing that Cartesian subjectivity must be reconceived as intersubjectivity. "Meanings just ain't in the head" is a slogan uniting pragmatists, cognitive scientists, feminist epistemologists, and others. ${ }^{7}$ With this emergent understanding of belief as nonrepresentational, embodied, intersubjective, and public, the study of belief cannot be called the study of "interiority."

Here is a quiz question that may better illuminate this idea of public belief. Who is the scholar who made it his task to bring this idea of public belief to the study of religion? He is the scholar who wrote the following: "The generalized attack on privacy theories of meaning is, since early Husserl and the later Wittgenstein, so much a part of modern thought that it need not be developed once more here. What is necessary is to see to it that the news of it reaches anthropology." The answer is: Clifford Geertz (1973: 12). Lincoln and Asad are correct that Gecrtz insists that meaningful actions necessarily involve beliefs: "You can't wink... without knowing what counts as winking" (12). Nevertheless, Geertz condemns the idea that beliefs are interior mental phenomena, calling this the cognitivist fallacy (12). Instead, Geertz

\footnotetext{
7 The quote is Hilary Putnam's (1975: 227).

${ }^{8}$ In my judgment, three milestones tracing the development of a nonrepresentational theory of knowledge are Rorty 1979, Bernstcin 1988, and Frisina 2002.
} 
says that what the members of a culture believe is "as public as marriage and as observable as agriculture" (91). I agree with Geertz's critics that he tends to insulate religious meanings from social and political networks of power, and so I appreciate $\Lambda$ sad's Focauldian idea of religion as discipline, and I admire and use Lincoln's more politically informed definition of religion. Nevertheless, Geertz's critics distort his project if they think that Geertz treats beliefs as private states of mind. ${ }^{9}$

Now, if this third option of public belief (inadequately sketched as it is) seems like a legitimate possibility, then it also seems to me that it is the position to which Lincoln is closest. I say this because Lincoln does not argue that those who study religion abandon belief, but merely that they replace it with the more publicly accessible "discourse." "Discourse" may or may not be believed by those who use it, but it is necessarily propositional. It cannot be equated with material interests. Moreover, Lincoln treats discourse as the privileged category: Lincoln is clear that an activity is a religious activity only if it is informed by religious discourse. ${ }^{10}$ Here the parallel to Geertz is striking. Por example, Geertz argues that what distinguishes the religious perspective from the aesthetic perspective is the symbols of the really real that induce religious moods and motivations (Geertz 1973: 111-2). Lincoln complains that in this privileging of the interior life, Geertz assumes a Protestant religiosity (1). But then Lincoln seems to make the same move, arguing that it is religious discourse that makes growing a beard a religious practice. "Lacking... [a] motive of this sort," Lincoln says a beard "represents a strictly aesthetic preference" (6). I see no epistemological difference between Geertz's appeal to "motivations" and Lincoln's appeal to "motive." Neither is, in my judgment, an appeal to private, inaccessible interiority, nor is either especially Protestant. Instead, Lincoln, like Geertz, is arguing that religious practices must have an at least implicit element of publicly available discursive or propositional thought in order to be identifiable as religious. In my judgment, this is the position, philosophically speaking, that they should take.

I am arguing, in other words, that, although the place of belief in different traditions is not the same, all religions involve belief. In Christian

${ }^{9}$ I develop this point in Schilbrack (forthcoming).

10 Thus Lincoln defines religious practices as: "A set of practices whose goal is to producc a proper world and/or proper human subjects, as defined by a religious discourse to which these practices are connected" $(6)$. The primacy given to discourse is also seen in that Lincoln has spoken of religion as simply discourse (Lincoln 1996: 225 [Thesis \#2]). 
theology, belief is traditionally taken as a cognitive dimension of faith (fides) and it is allied with trust (fiducia) as its emotional/affective dimension and with loyalty (fidelitas) as its motivational/conative dimension. From this (admittedly parochial) perspective, to say that non-Christian religions lack "belief" would be to say that the practices of religions outside the Christian influence are noncognitive. It is hard to see that such a working assumption is less ethnocentric than its opposite. Similarly, to assume that belief refers to an inward state is to take what Christians or rather, some Christians, and especially Luther - have meant by the term and turn this into a general definition. ${ }^{11}$ What is needed, instead, is to trace in each particular case the presence or absence of such categories in the practitioners themselves.

To be clear, then, Lincoln and I agree that religion is to be studied as a social fact, not as a psychological entity located in individual minds, and we also agree that a believer's discourse may not correspond to what she privately affirms. It may therefore seem that the disagreement between us is merely verbal: what he distinguishes as discourse and belief, I am calling public belief and private affirmation. Nevertheless, the difference is more than verbal because Lincoln's vocabulary (which separates religion into external "expressions" of which outsiders can have "direct knowledge" and "interior" beliefs to which outsiders have "no unmediated access") is dualistic. To define belief as private rather than as a public leads to a Cartesian anxiety in which it makes sense to point out, for example, that Christians say that Jesus is divine, but the student of religion cannot know that any Christian has ever believed this. The view that beliefs are permanently inaccessible builds epistemological doubt into one's theory. Here, like the contents of a box that can never be opened, "belief" becomes a transcendent or noumenal term and plays no role in understanding or explaining religion. Lopez's view that "belief" can be eliminated is the conclusion of such reasoning. On my view, by contrast, the statement "The pilgrims washed themselves at the shrine because they believed that doing so might heal them" is perfectly legitimate. $\Lambda$ s long as "belief" means public belief, to replace that formulation with " $\Lambda$ ccording to their discourse, washing themselves at the shrine might heal them" is not merely pedantic or superfluous. It burdens the study of religion with a mind-

\footnotetext{
"For an astute history of the term in Christian thought and practice, and an argument that religions other than Christianity lack belief as a comparable organizing concept, see Ruel 1982.
} 
body dualism that is doubly problematic: it is rarely shared by the religions studied and it has been widely discredited in contemporary philosophy.

\section{Lincoln on "experience"}

We have seen that Lincoln gives reasons for why he did not want to include the category of belief in his definition of religion. About the category of "experience," however, he has little to say. It is not only not part of his definition of religion; "experience" does not show up in the index of any of his books. Of course, this is deliberate, and this silence places Lincoln's work on one side of a contemporary debate about the nature of religion and how best to study it. On the question of experience, therefore, Lincoln does not take a middle path; he represents one of the two poles. For this reason, as one might guess, I will argue that his approach leaves something to be desired. ${ }^{12}$

What are the two contrary positions on the place of "experience" in the study of religion? In the first place, there are those who define religion precisely in terms of experience. For this camp, the heart of religion is not a matter of assenting to a certain creed, nor performing certain ethical or ritual actions. Rather, the heart of religion is having a certain kind of experience. The key figure in the emergence of this position is Friedrich Schleiermacher, who sought, in the wake of Kant's critiques, to distinguish "true religion" from the beleaguered domains of belief and practice, which Schleiermacher argued are merely its expressions. I do not believe that this is the dominant position in the study of religion, but it has clearly been an influential one, and there is a direct line of influence from Schleiermacher to the anti-reductionist programs of Rudolf Otto and to Mircea Eliade. Call this the experientialist position.

In the second camp are those who define religion with no reference at all to religious experience. From this perspective, religion is a language game, a discourse, or a system of representations, and experience is otiose. I am putting Lincoln in this camp. Those who take this second position often do their theorizing in reaction to the first camp and the way in which Christian apologetic concerns have worked their way into the study of religion. In our day, the pendulum is swinging or has

12 This section draws inspiration from Csordas 1999. 
already swung away from the study of religion as the study of modes of experience or the feeling of the sacred, to the study of religion as discourse or text. Call this the semiotic approach. ${ }^{13}$

In this context, I want to ask whether the semiotic approach has swung the pendulum too far, whether or not there is a position that better synthesizes its insights with those of the experientialist position. Towards this goal, I want to point to what I take to be two shortcomings of an exclusively semiotic approach, one descriptive and the other more theoretical.

The descriptive problem is that the semiotic approach ignores a central dimension of religion as it is lived. Consider an example from Dennis Covington's journalistic account of the practices of a snake-handling church in Alabama (Covington 1995). With eloquence and affection, Covington explores the practices of this Appalachian church, giving special attention to the ecstasies of holding the rattlesnakes and of speaking in tongues. In the course of his account, he describes a man whose wife had gotten the Holy Ghost at a service and who wanted to get it, finally, for himself. This desire is completely understood by the others in the congregation. So, a half dozen men pray over him and lay hands on him, and the man is "up and running from one end of the sanctuary to the other, now twirling, now swooning, now collapsing once again on the floor, his eyes like the eyes of a horse that smells smoke, the unknown tongue spewing from his mouth" (167). All of this, I believe, Lincoln could include under the category of practice. After the service, however, as the man brushes sandwich crumbs from his lap, he says to Covington that "it was a good service all right, but it sure would have been better if he'd only gotten the Holy Ghost" (168). So, in the eyes of this man, and also in the eyes of the congregation at large, something was missing, and this was something precious. The man was fully religious according to Lincoln's definition; he was participating in the discourse of his religion, in its practices, community, and institutions. But what matters to him is how it feels to be reli-

13. In terms of these two approaches, one can see that again, ironically, Lincoln is close to Gecrtz. Por following Paul Ricocur's argument that one can treat actions like texts (Ricoeur 1991), Geertz treats religious rituals as public documents that can be read for their meaning (for Gecrtz's acknowledgement of Ricocur, sec 1973:19). Says Geertz: "The concept of culture I espouse . . . is essentially a semiotic onc.... Doing ethnography is like trying to read ... a manuscript" (1973: 5, 10). In a critique that parallels my critique of Lincoln, Tyson (1988) and Stoller (1997) complain that Gectz's semiotic approach ignores the sensual aspects of religion as lived. 
gious, what some scholars might call the formation of his religious affects and subjectivity, his religious mode of being in the world; what is missing, in short, is a phenomenological dimension. This is what is not included in a purely semiotic approach. The descriptive problem of the semiotic approach, in other words, is that experience has fallen out of the theorizing, and so this approach treats religion in terms of what are, from a phenomenological perspective, objectified abstractions. Thus with Lincoln one studies not the piety of the Mohamed $\Lambda$ tta, but the document he left in his car. ${ }^{14}$

Predictably, I think that the theoretical problem with the semiotic approach concerns its implicit philosophy. Of course, from my perspective, both the experiential approach and the semiotic approach involve philosophical decisions. I want to focus in particular on the decisions they embody concerning the relation of language to experience, of word to world. Some argue that Schleiermacher holds that religious experience is able to circumvent the categories of language in order to have immediate connection with its object. Whether or not Schleiermacher himself is guilty of this, such a position would be deeply problematic for, as Wayne Proudfoot argues, "[i]f the feeling is intentional [that is, if it is the feeling of an object], it cannot be specified apart from reference to its object and thus it cannot be independent of thought" (Proudfoot 1985: 11). The problem here is the need to identify an experience unmediated by concepts.

The semiotic approach also seeks to come to terms with the relation of word to world, and it also stumbles. The problem, in brief, is that this approach inherits the question of the relation of language to experience, but its solution is not to reconcile or bridge the two realms but simply to drop experience out. From this semiotic perspective, correspondence theories of truth are unintelligible and all forms of realism are naive. The only data available to the scholar of religion are linguistic: texts, systems of representation, discourse, "marked categories" (Lincoln 2000). Here, pieces of language connect only to other pieces of language and the referential question - linguistic representation of what? - cannot be meaningfully asked. $\Lambda$ s the primary spokesperson for this philosophical movement says, "There is no outside-the-text."

1t At this point, one ean see that Lincoln's account of belief as something private that does not play a role in understanding or explaining religion implies and is implicd by his "scmiotic" approach that fails to include allegedly private religious experiences. 
What might be a middle position here? From my perspective as a philosopher, the best position for the study of religion will be one that is able to negotiate the relation of religious language to religious experience in a satisfactory way; it will be one that is least entangled in epistemological puzzles. For my money, this will be a position that treats religious experience as neither diamond nor paste. That is, religious experience should not be lifted up as the inexpressible essence of religion, unsullied by language and history, nor should it be discarded as merely the internal echo of social discourse, merely a reflection of ideology. In other words, the balanced position will be one that is both phenomenological and semiotic. It will be a position that says "yes" both to the inclusion of experience as a dimension of religion and to the recognition that experience is always shaped in part by language. Put negatively, it will say "no" both to the idea that one might identify an experience as religious without using human concepts, and to the idea that experience is fully constituted by language.

Students of religion should not let the claims that religious experience is sui generis or autonomous from belief, and allow this practice to goad them to over-react and underemphasize the place of experience in the history of religions. If religious traditions label certain bodily and mental states religious, then such experiences should not be excluded from the study of religion, let alone defined out of existence. The fact that a certain discourse must be in place and employed in order for someone to experience a religious experience does not mean that the analysis of discourse exhausts the study of religion, any more than the analysis of fuel would exhaust the study of fire. Moreover, to distinguish between declaration of conviction and actual conviction, between the profession of a faith and the transformation of a heart, and in general between exoteric and esoteric aspects of a religion is not limited to modern examples. Nor is it limited to Christianity: thus the distinction in Islam between the visible surrender (islam) and the faith (iman) of the believer (mu'min). To operate with both the category of discourse and that of experience reflects a distinction that will be recognized by all religions that have a concept of sincerity.

What does this mean for Lincoln's definition of religion? I don't think that "experience" needs to be added to Lincoln's four-part definition of religion. To call the man in Covington's book religious would not misidentify him. His discourse, practice, and community are all plainly religious. In fact, even his lack of religious experience is religious. So as a tool that does not identify the essence of religion but helps us to clarify our thinking about the world in which we live, Lincoln's 
definition is helpful - and more helpful than many others. Lincoln's definition works as is. Nevertheless, on the larger question whether religious experience is a legitimate object of study, I hold that it is. There is an important relationship between religion as a public fact (that is, Lincoln's definition) and the creative agency of the embodied human subject, and this relationship calls for a phenomenological element in religious studies. ${ }^{15}$

Wesleyan College

4760 Forsyth Road

Macon, Georgia 31210-4462

\section{References}

Asad, Talal (1993). Genealogies of Religion: Discipline and Reasons of Power in Christianity and Islam. Baltimore: The John Hopkins University Press.

Covington, Dennis (1995). Salvation on Sand Mountain: Snake Handling and Redemption in Southem Appalachia. New York: Penguin Books.

Csordas, Thomas J. (1999). Embodiment and cultural phenomenology. In Gail Weiss and Honi Fern Habcr (cds), Perspectives on Embodiment: The Intersections of Nature and Cullure, 143-62. New York: Routledge.

Geertz, Clifford (1973). The Interpretation of Cultures. New York: Basic Books.

Godlove, Jr., Terry F. (2002). Saving belicf: On the new matcrialism in religious studies. In Nancy K. Frankenberry (ed.), Radical Interpretation in Religion, 10-24. Cambridge: Cambridge University Press.

Hartshorne, Charles (1987). Wisdom as moderation: A philosophy of the middle way. Albany: State University of New York Press.

Lincoln, Bruce (1996). Theses on method. Method and Theory in the Study of Religion $8(3): 225-7$.

- (2000). On ritual, change, and marked categorics. Joumal of the American Academy of Religion 68(3): 487-510.

(2003). Holy Terrors: Thinking about Religion after September 11. Chicago: University of Chicago Press.

Lopez, Jr., Donald S. (1998), Belief. In Mark C. Taylor (ed.), Critical Terms for Religious Studies, 21-35. Chicago: The University of Chicago Press.

Proudfoot, Wayne (1985). Religious Experience. Berkclcy: University of California Press.

Putnam, Hilary (1975). The meaning of 'meaning.' In Mind, Language, and Reality: Philosophical Papers, vol. 2, 215-71. Cambridge: Cambridge University Press.

Ricocur, Paul (1991). The model of a text: Mcaningful action considered as a text. In From Text to Action: Essay in Hermeneutics, II, 144-67. Evanston, Ill.: Northwestern University Press.

Ruel, Malcolm (1982). Christians as belicvers. In J. Davis (ed.), Religious Organization and Religious Experience. London: Academic Press.

\footnotetext{
${ }^{15}$ I would like to thank Phil Devenish and Franklin Gamwell for comments that improved this paper.
} 
Schilbrack, Kevin (forthcoming). Religion, models of, and reality: Are we through with Gccrtz? Joumal of the American Academy of Religion.

Stark, Rodney (2003). For the Glory of God: How Monotheism Led to Reformations, Science, Witch-Hunis, and the End of Slavery. Princeton: Princeton University Press.

Stoller, Paul (1997). Sensuous Scholarship. Philadelphia: University of Pennsylvania Press.

Tyson, Jr., Rucl W. (1988). Culture's 'hum and buzz' of implication: The practice of ethnography and the provocations of Clifford Geertz's 'Thick Descriptions.' Soundings 71: 95-111.

Wiebe, Donald (1999). The Politics of Religious Studies: The Continuing Conflict with Theology in the Academy. New York: St. Martin's Press. 